\title{
Should we be advocates for injury prevention?
}

When the International Society for Child and Adolescent Injury Prevention (ISCAIP) was created, one of its explicit goals, among others, was to 'promote advocacy at national and international levels'. Why should ISCAIP be an advocacy organization? What should the Society advocate for and how should it go about being an advocate?

I hope that most of us would agree that there are many reasons why ISCAIP should assume an advocacy role for the prevention of injuries to children and adolescents. Injuries are the most important cause of death for children and adolescents in all of the developed countries of the world and for many of the developing countries as well, as discussed in the Regional Reports in this issue of the journal. Nevertheless, prevention of injuries is not a priority in many, if not most, countries. For example, it was only through the advocacy efforts of Hugh Jackson and others that Great Britain within the last five years included injury prevention as one of its top 10 health policy issues. In the US, the National Center for Injury Prevention and Control wasn't established until the 1985 report Injury in America reinforced the importance of the injury problem and advocated for the designation of a single government agency to lead national injury prevention and research efforts.

Even among countries in which injury is a recognized problem, efforts to include children and adolescents as a priority are necessary. The old adage that 'children don't vote' is true, and most health budgets are driven by the needs and costs of adults, particularly the elderly, and not by children whose care accounts for a much smaller portion of the budget and whose early deaths do not affect current societal productivity (although they may affect productivity in the future).

In most countries, there are no organized efforts to promote injury prevention. In many other countries, lone individuals work with little support to bring the injury problem to public attention, like $\mathbf{R}$ Krishnan in Malaysia and Dinesh Mohan in India. In contrast, efforts that are organized and focused have made substantial impacts on the injury problem. The Committee for Child Accident Prevention established 40 years ago by Ragnar Berfenstam has been enormously successful in lowering the injury rates in Sweden and getting injury control incorporated into the very fabric of Swedish society. The Child Accident Prevention Trust, established by Hugh Jackson, has been a leader in non-governmental agencies working on behalf of the safety of children.

Efforts such as these must be duplicated around the world. I believe that ISCAIP can have a major impact on the growth of these efforts by serving as an advocate for them. The force of an international organization can lend credibility to the efforts of the lone voice in the wilderness, perhaps enough to make a difference in the establishment and funding levels of such programs.

What then should we advocate for? The answer, I believe, lies in what is necessary for countries, whether they be developed or developing, to have effective programs to reduce morbidity and mortality to children and adolescents from injuries. Here is my short list of priorities:

- Injury surveillance: The backbone of any injury preven- tion or research program must be accurate determination of the magnitude of the problem, the types of injuriesw occurring, and the groups at greatest risk. Surveillance is one of the traditional and most basic of public health functions, but one which is sorely lacking in many $\vec{\omega}$ developing countries. Complete determination of theo number of deaths due to injuires is a necessary, although not sufficient, start. Such data need to be reliable enough to $\omega$ detect trends over time, highlight differences between regions, and identify the groups at greatest risk. Mortalityo data must be supplemented with morbidity data, including for example information on motor vehicle crashes hospita- $\overrightarrow{-}$ lizations for trauma, and calls to poison control centers.

- Injuries as a public health problem: Injury prevention is best approached from a population perspective, rather than through a focus on individual risk factors and intervention. $\Phi$ Since public health agencies are responsible for the health $\vec{\bullet}$ of the population in a country, injuries must be viewed as a public health problem and placed on the public health agenda. The attention devoted to injuries should beo congruent with the importance of the problem as a cause of years of life lost and disability in that country.

- Resources for injury control: Volunteer efforts have been⿳亠े very important in the development and implementation of injury control strategies, but they can only go so far.을 Commitment of resources is necessary to have a continued and long term impact on the injury problem. These resources need to be appropriate relative to the funds available and the magnitude of the problem. Unfortunately, this is still not the case even for countries such as the US and the UK.

- Designation of a lead agency: Countries which have made the most difference in injury control have had a single group leading and coordinating the effort. Resources are far? too scarce to be spent on duplicative services by competing agencies. Whether this agency should be exclusively. devoted to child and adolescent injury prevention or $\frac{\text { ? }}{3}$ whether it can and should serve the broader role for all

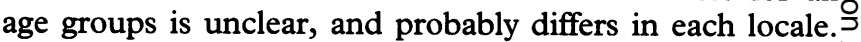
Agencies with an exclusive child and adolescent focus willo safeguard the interests of children better but may do so at the expense of less political clout than agencies representingo adult preventive efforts as well.

Finally, how should ISCAIP, as a professional organiza-N tion, act as an international advocate for child and $\sigma^{\omega}$ adolescent injury prevention? Here is a modest proposal.

- Support member efforts: ISCAIP should respond to

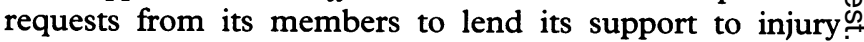
control efforts in their countries. These requests could 0 be submitted to the board for their approval and a letter

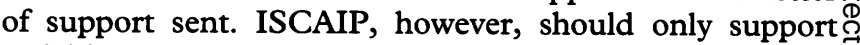
activities shown to have been effective in reducing $\stackrel{\mathbb{Q}}{\mathscr{Q}}$ injuries.

- Take positions: ISCAIP should take positions on issues that cut across national boundaries. We live in a world in which products are marketed internationally and standards are set which affect children in many countries. Equipment manufacturers of, for example, bicycle helmets or child seat restraints, sell their products in the international market. ISCAIP should lobby for some uniformity of these 
standards to ensure that all children benefit from the most protective products, and that less protective devices are not sold in some, particularly developing countries. This would recuire that ISCAIP establish a public policy committee with the necessary expertise and interest to make appropriate recommendations.

- Track efforts or lack thereof: ISCAIP should track international trends in injury mortality among children and adolescents, and efforts in each country to reduce the toll from injuries. Comparisons of infant mortality have been used as markers of a nation's maternal and child health care and have spurred efforts to improve such care. Might we accomplish the same for injury control through tracking and publication of international comparisons of injury mortality rates?

ISCAIP is an organization founded to serve its members' needs and to reflect its members' goals. Advocacy is one potential way for the society to serve these needs. I've outlined here a modest proposal for an advocacy agenda which I hope will start a dialogue about its merits and details in these pages, on ISCAIPNET, and at the 4th World Conference on Injury Prevention and Control in Amsterdam in May 1998. Speak up and be heard; we're listening!

FREDERICK P RIVARA Chair, ISCAIP

Harborview Injury Prevention and Research Centre, Box 359960, 325 Ninth Ave,

Seattle, WA 98104, USA

(Phone +1 206521 1530; fax +1 206521 1562; e-mail fpr@u.washington.edu)

\section{Editorial Board Member: brief biography}

JAN SHIELD

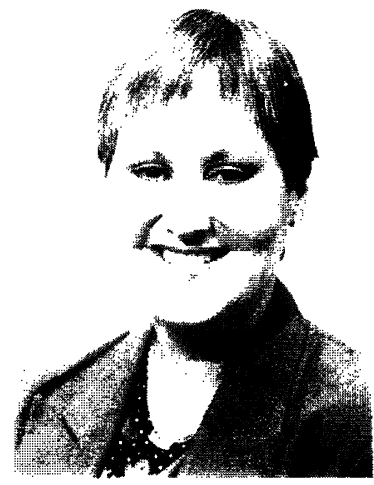

Jan Shield, BA, Dip Ed, Grad Dip Information Services, of the Royal Children's Hospital Safety Centre, Melbourne, was involved in the organisation of the Third International Conference on Injury Prevention and Control. The Safety Centre, the first of its kind in the world, was one of the most popular site visits for the conference. Most of you will know her, however, as the editor of the 'Splinters \& Fragments' page in this journal. She brings to this role long experience at reviewing and abstracting injury prevention literature for the current awareness bulletin, Child Safety News, which she has edited since 1989.

Her work as a safety consultant involves such diverse activities as health education, development of resources for use with parents, health professionals and childcare providers, editing other publications, lecturing students, running workshops for parents and professionals, and participating in professional injury control bodies, including the Victorian Community Council Against Violence and the Victorian Injury Control Forum.

Jan's professional interests are in the areas of child and adolescent injury prevention, increasingly focused towards the prevention of intentional injury, violence, and self harm. She is particularly interested in interpreting the results of research into a form easily understood by the general community, and in ensuring that appropriate interventions are promoted for the community. Although her background is in the social sciences, she is currently studying for an MPH degree at Monash University. The topic for her thesis is an injury related public health issue: youth suicide by gunshot. 